\title{
Composition of Picocyanobacteria Community in The Great Mazurian Lakes: Isolation of Phycoerythrin-Rich and Phycocyanin-Rich Ecotypes from the System - Comparison of two Methods
}

\author{
IWONA JASSER $^{1 *}$, ANNA KARNKOWSKA-ISHIKAWA ${ }^{2}$, EWA KOZŁOWSKA ${ }^{3}$, ADRIANA KRÓLICKA ${ }^{1}$ \\ and MAJA ŁUKOMSKA-KOWALCZYK ${ }^{1}$

\begin{abstract}
${ }^{1}$ Microbial Ecology Department, Institute of Botany, Faculty of Biology, University of Warsaw, Poland
${ }^{2}$ Department of Plant Systematics and Geography, Institute of Botany, Faculty of Biology, University of Warsaw

${ }^{3}$ Department of Immunology, Institute of Zoology, Faculty of Biology, University of Warsaw
\end{abstract}

Received 15 September 2009, accepted January 2010

\begin{abstract}
The study showed that the picocyanobacteria community of the Great Mazurian Lakes system (GML) was dominated by phycoerythrinrich (PE) ecotypes and demonstrated a gradual decrease of the ratio between PE and phycocyanin-rich (PC) ecotypes. The Great Mazurian Lakes offer better conditions for the PE ecotype than for the PC one, despite the considerably high trophic status, probably thanks to low turbidity and attenuation of light in the water column. The successful isolation of PE and PC picocyanobacteria was achieved by two methods: the classic plate method and a modified flow-cytometry method. The modified flow-cytometry method proved to be superior: being more selective for PE picocyanobacteria as well as less time consuming and less laborious. The modifications introduced to the method, such us concentration of cyanobacterial cells by centrifugation to the density required by the flow cytometer, did not hinder the isolation while allowing to skip an intermediate phase of enrichment cultures that had been formerly proposed. The first phylogenetic analyses based on $c p c B A$ operon and $16 \mathrm{~S}$ rRNA gene demonstrated that picocyanobacteria isolates from GML could, with a high bootstrap support, be grouped into five and four clusters, respectively. Based on a $c p c B A$-IGS analysis and IGS length the study suggests that at least one of the clusters is new and has not been previously described.
\end{abstract}

K e y words: ecotypes isolation, flow-cytometry, freshwater picocyanobacteria, phycocyanin, phycoerythrin

\section{Introduction}

Autotrophic picoplankton (APP), discovered and described in the late 1970s (Johnson and Sieburth, 1979; Waterbury et al., 1979) is still the least known phytoplankton component of both marine, and especially, freshwater environments. The development of fluorescent microscopy, flow-cytometry and molecular techniques allowed better study of these microorganisms and thus the basic facts and rules concerning the occurrence, composition and seasonality of the APP community have been discovered. The investigations of seasonal dynamics of APP revealed that in temperate waters it usually exhibits a biphasic pattern with two peaks of abundance - one in the spring and the other in late summer (Stockner, 1991; Weisse, 1993; Hepperle and Krienitz, 2001; Jasser and Arvola, 2003). However, patterns with a single peak occur- ring in early or late summer were also described (Søndergaard, 1991; Jasser, 2002), sometimes even for the same lakes from which a biphasic patterns were reported before, as was the case for Lake Biwa (Wakabayashi and Ichise, 2004).

The number and biomass of APP rises with the increase of trophic status. However, the significance of the community in total phytoplankton generally decreases. Thus APP is considered to be especially important in oligotrophic and mesotrophic environments where it functions as the basic primary producer (Agawin et al., 2000; Bell and Kalff, 2001; Callieri and Stockner, 2002). Yet, even in a eutrophic environment, APP may be an important food source for grazers, especially during periods when phytoplankton is dominated by inedible forms (Callieri and Stockner, 2002). There are also reports of highly productive systems occasionally dominated by autotrophic

* Corresponding author: I. Jasser, Microbial Ecology Department, Institute of Botany, University of Warsaw, ul. Miecznikowa 1, 02-096 Warsaw, Poland; phone (+48) 22 5541444; e-mail: jasser.iwona@biol.uw.edu.pl 
picoplankton biomass and/or production (Carrick and Shelske, 1997; Hepperle and Krienitz, 2001; Jasser et al., 2009).

As regards community composition in freshwaters, APP is represented mainly by phycoerythrin-rich (PE) picocyanobacteria, which dominate in oligotrophic and mesotrophic environments, while in more productive waters phycocyanin-rich (PC) picocyanobacteria and picoeukaryotes tend to dominate the community (Vörös et al., 1998). Additionally in the winter and early spring picoeukaryotes are believed to dominate in all temperate waters, regardless of their trophic status (Mózes et al., 2006).

The regularities quoted above show that APP exhibits high functional variability but the key factors which shape this variability are still poorly known. Temperature, nutrient concentration and light climate of ecosystems are among the main factors influencing the occurrence and seasonality as well as domination of either PE or PC ecotype (Vörös et al., 1998; Jasser and Arvola, 2003; Stomp et al., 2007; Haverkamp et al., 2008). The dispersal and genetic diversity of picocyanobacteria has been studied for the past two decades although the data is still sparse and omits many geographical regions (Ernst, 1991; Ernst et al., 2003; Crosbie et al., 2003a; Haverkamp et al., 2008). Among them is the Great Mazurian Lakes system (GML), situated in a Mazurian Lakeland in northeastern Poland. Up till now there had been no picocyanobacteria isolated from these lakes for use in ecophysiological or genetic and molecular studies.
The lakes in the GML are interconnected naturally or by man-made canals and the waterway runs NorthSouth for over $100 \mathrm{~km}$. It consists of lakes characterized by various trophic status (Chróst and Siuda, 2006), ranging between mesotrophy (with 40 mean trophic state index - TSI, Carlson, 1977) to hypertrophy (with 72 mean TSI). The system, located in the same geographical area and similar geological substratum, has lakes that differ in the trophic status as well as underwater light climate thus serving as an ideal location for autotrophic picoplankton studies.

The aim of the present study was to: (i) establish the composition and abundance of picocyanobacteria in the Great Mazurian Lakes system, (ii) isolate picocyanobacteria from several lakes belonging to GML and compare two isolation methods: the classic plate method and a modified flow-cytometry method proposed by Crosbie et al. (2003b) and finally (iii) to characterize the phylogenetic relationships between the isolated strains.

\section{Experimental}

\section{Materials and Methods}

Sampling. Fifteen lakes from the Great Mazurian Lake system (GML) situated in northeastern Poland $\left(54^{\circ} \mathrm{N}\right.$ and $22^{\circ} \mathrm{E}$ ) as well as mesotrophic Lake Majcz Wielki, not directly connected with the system, were sampled in July and early September in 2006 in order

Table I

Basic morphological parameters, mean summer values for chlorophyll $a$, total phosphorus and Secchi depth as well as mean Carlson's index (TSI) and summer $\mathrm{K}_{\mathrm{SD}}$ values of the studied lakes

\begin{tabular}{|l|r|r|r|r|r|c|c|}
\hline \multicolumn{1}{|c|}{ Lake* $^{\text {Area }}$} & $\begin{array}{c}\text { Mean Depth } \\
(\mathrm{ha})\end{array}$ & $\begin{array}{c}\mathrm{TP} \\
\left(\mu \mathrm{mol} \mathrm{l^{-1 }}\right)\end{array}$ & $\begin{array}{c}\text { Chl. } a \\
\left(\mu \mathrm{g} \mathrm{l^{-1 }}\right)\end{array}$ & $\begin{array}{c}\text { SD } \\
(\mathrm{m})\end{array}$ & $\begin{array}{c}\text { Carlson's index } \\
(\mathrm{TSI})\end{array}$ & $\mathrm{K}_{\mathrm{SD}}$ \\
\hline Przystań & 115 & 11.3 & 0.4 & 3.3 & 3.8 & 41.0 & 0.38 \\
\hline Mamry & 2504 & 11.7 & 0.3 & 3.6 & 3.3 & 40.7 & 0.44 \\
\hline Majcz Wielki & 160 & 6.0 & 1.3 & 5.0 & 4.0 & 47.3 & 0.35 \\
\hline Dargin & 2680 & 10.6 & 0.9 & 10.9 & 3.3 & 49.6 & 0.44 \\
\hline Łabap & 350 & 8.5 & 0.9 & 9.6 & 2.9 & 49.8 & 0.50 \\
\hline Kisajno & 1896 & 8.4 & 0.9 & 14.1 & 2.7 & 51.4 & 0.54 \\
\hline Śniardwy & 11340 & 5.8 & 1.1 & 12.3 & 2.2 & 53.0 & 0.66 \\
\hline Niegocin & 2600 & 10.0 & 1.8 & 22.1 & 2.0 & 57.7 & 0.73 \\
\hline Bełdany & 941 & 10.0 & 1.8 & 24.7 & 1.3 & 60.1 & 1.12 \\
\hline Tałty & 1160 & 13.5 & 1.9 & 25.7 & 1.8 & 59.3 & 0.81 \\
\hline Ryńskie & 671 & 13.5 & 2.1 & 31.2 & 1.6 & 60.1 & 0.91 \\
\hline Mikołajskie & 498 & 11.2 & 1.9 & 33.1 & 1.4 & 61.6 & 1.04 \\
\hline Jagodne & 420 & 8.7 & 2.2 & 47.2 & 1.2 & 64.3 & 1.21 \\
\hline Szymoneckie & 523 & 8.7 & 2.8 & 61.5 & 1.0 & 67.3 & 1.45 \\
\hline Szymon & 154 & 1.1 & 2.6 & 84.2 & 0.6 & 70.6 & 2.42 \\
\hline Tałtowisko & 327 & 14.0 & 2.8 & 87.3 & 0.5 & 72.1 & 2.90 \\
\hline
\end{tabular}

* Modified after Chróst and Siuda (2006); Lake Majcz Wielki (Jasser, 2006) 
to establish the abundance and domination of $\mathrm{PE}$ or PC picocyanobacteria. The lakes differ in their trophic status, size and depth (Table I).

Four lakes (mesotrophic Lake Majcz Wielki, mesoeutrophic Lake Śniardwy and eutrophic Lake Mikołajskie and Bełdany) were sampled in 2007 to isolate picocyanobacteria. Sampling was performed eight times between April and October. Each time the samples were collected from Lake Mikołajskie, while other lakes were sampled irregularly. Water was drawn from epilimnion of the studied lakes, stored in open plastic containers in a cool, dark place in the field station and transported as soon as possible (usually within 1-2 days) to the laboratory. In the laboratory the samples were filtered by gravity in sterile Sartorius filtration units through $2.0 \mu \mathrm{m}$ polycarbonate membranes. On a few occasions, when microscopic analysis showed contamination by algae and cyanobacteria bigger than $2 \mu \mathrm{m}$, the water was additionally passed through membranes of $1.2 \mu \mathrm{m}$ pore size. After filtration two approaches were used: enrichment cultures according to Crosbie et al. (2003b) and/or the direct isolation of filtered natural samples. Enrichment cultures consisted of $200 \mathrm{ml}$ of lake water filtrate and $50 \mathrm{ml}$ of medium BG11 (Stanier et al., 1971) or BG11 modified (Ernst et al., 2005). The procedure of filtration and amending with the medium was repeated every week for 3-4 weeks. After this either the classic plate method or the flow-cytometry method was followed. However, from June, only the direct isolation of filtered natural samples was performed. In addition to isolation, the abundance and composition of the APP community in the studied lakes were checked and the percentage share of PE and PC cells was calculated.

Media. Three media types were used for the isolation of picocyanobacteria: standard BG11 (Stanier et al., 1971), modified BG11 (Ernst et al., 2005) and WC medium (Guillard and Lorenzen, 1972). The media differed mainly in $\mathrm{N}$ and $\mathrm{P}$ content, as well as N:P ratios. The modified BG11 medium had the $\mathrm{N}$ and $\mathrm{P}$ concentration reduced to $1 / 3$ but the $\mathrm{N}: \mathrm{P}$ ratio remained similar as in the original BG11. WC medium had an $\mathrm{N}$ concentration reduced to $14 \mathrm{mg} \mathrm{N}^{-1}$ and $\mathrm{P}$ to $1.57 \mathrm{mg} \mathrm{P}^{-1}$. As a consequence the molar $\mathrm{N}: \mathrm{P}$ ratio in WC was 20:1 in comparison to 100:1 molar ratio in the standard and modified BG11.

Classic plate method. The classic plate method (Ernst, 1991; Watanabe et al., 1998) with media solidified by Difco agar $(0.6 \%, \mathrm{w} / \mathrm{v})$ was used. The filtered samples of lake water or enrichment cultures were spread with a sterile spreader over $20 \mathrm{ml}$ of given medium in Petri dishes, covered and sealed by Parafilm. The samples were incubated in an inverted position at $18^{\circ} \mathrm{C}$ (in the spring) and $21^{\circ} \mathrm{C}$ (in the summer). "Coolwhite" fluorescent tubes provided light of $7 \mu \mathrm{mol} \mathrm{m}^{-2} \mathrm{~s}^{-1}$ in a $14 / 10$ hour day/night cycle. After 10 to 40 weeks the red and green colonies formed on agar were analyzed under the fluorescent microscope to check if they were APP colonies. Verified APP colonies were then aseptically transferred by streaking to other Petri dishes to obtain pure colonies. After growth of red or green APP was achieved, the colonies were inoculated into a liquid medium of the same type on which the cells were isolated. In July, August and October the media were enriched with $200 \mathrm{mg}^{-1}$ of cycloheximide and $100 \mathrm{mg}^{-1}$ of colchicine, inhibitors blocking protein translation and mitotic division of eukaryotes (Sherr et al., 1986).

Modified flow-cytometry method. The second method of picocyanobacteria isolation was a modified flow-cytometry method proposed by Crosbie et al. (2003b). For the flow-sorter a FACSCalibur equipped with $488 \mathrm{~nm}$ laser was used. The sorter was calibrated according to the reference strains: Synechococcus rubescens (SAG 3.81) for PE picocyanobacteria, PCC 6307 and PCC 7918 for PC picocyanobacteria and Choricystis minor (SAG 17.98) for the eukaryotic picoplankton (EAP). The reference strains were obtained from the Culture Collection of Algae (SAG) at the University of Göttingen ( $S$. rubescens and $C$. minor) and Pasteur Culture Collection in the case of both PC strains. Sort gates were targeting PE and PC picocyanobacteria and EAP. The samples were sorted twice, targeting chosen type of PE or PC cells to reduce the possibility of contamination of sorted material by cells characterized by another fluorescence type or size.

Prior to sorting, the filtered natural samples or enrichment cultures were centrifuged for $20 \mathrm{~min}$ by $3500 \times \mathrm{g}$ to obtain a density of about $10^{6} \mathrm{cells}^{-1}$. Then the cells were suspended in $0.1 \%$ autoclaved $\mathrm{NaCl} \mathrm{PBS}$, and sorted to $50 \mathrm{ml}$ falcon tubes. The process was stopped when ca 50,000 cells were sorted. The sorting was repeated and the obtained cells were centrifuged (once again) to separate them from PBS and suspended in the chosen medium. The medium with sorted cells were distributed between 24 or 48 microwells of $2.5 \mathrm{ml}$. The final number of cells per well was about 1000 . The microwells were covered with a lid and incubated in standard conditions. After 4 to 10 weeks the growth of cells was observed as a red or green coloration of the medium. The wells with cell growth were checked for the presence of desired picocyanobacteria type. After a few weeks (when the density of chosen isolates achieved $\mathrm{Ca} 10^{7}$ cells $\mathrm{ml}^{-1}$ ), $1.25 \mathrm{ml}$ of the cultures were transferred aseptically to sterile test tubes and filled with $3.75 \mathrm{ml}$ of the medium in which each culture was grown. After a couple of weeks the APP was analyzed microscopically to check if the cultures contained only one type of cyanobacterial cells and then transferred to sterile 
glass flasks filled with $15 \mathrm{ml}$ of the medium. The obtained isolates were then sorted again and the sorted cells were inoculated into $0.1 \mathrm{ml}$ microwells with the final number of 0.5 cells per well. The putative isolates were cultured in standard conditions and the procedure of transferring the isolates to larger volume of used media was repeated till we obtained $15 \mathrm{ml}$ of desired strain, which were further cultivated and analyzed.

The isolation efficiency of each method was calculated. In the case of the plate method the number of streak plates was compared with the number of pure isolates (confirmed by molecular analysis) in liquid culture. In the case of the flow-cytometry method the number of microwells with sorted cells was compared with the number of pure isolates.

Microscopic analyses. Lake water samples for microscopic analyses were fixed with pre-filtered (GF/F Whatman filters) formaldehyde to a final concentration of $1 \%$ and stored in darkness at $4^{\circ} \mathrm{C}$ (Malinsky-Rushansky and Berman, 1991). The isolates were first examined as fresh samples but fixed samples were stored (as lake samples) for detailed morphological analysis. 5 to $10 \mathrm{ml}$ of lake water and about $0.1 \mathrm{ml}$ of isolates were filtered onto $0.2 \mu \mathrm{m}$ pore size black polycarbonate membranes, mounted on a slide with a drop of $50 \%$ glycerol and covered with a cover slip. The slides were examined under a 1,000 $\times$ magnification under a NIKON Eclipse fluorescent microscope equipped with a $100 \mathrm{~W}$ halogen lamp, a colour digital camera (Nikon DXM 1200F) and NIS Elements software for an image analysis system. At least 20 fields or 400 picocyanobacteria cells were counted. Initially two sets of filters: blue B-2A (DM $510 \mathrm{~nm}$, Ex 450-490 nm and BA $520 \mathrm{~nm}$ ) and green G-2A (DM 580, Ex 510-560 and BA 590) were used. However later, a new filter CY3 (HYQ) with Ex 530-560nm, DM 570nm, BA 573-648 nm was tested and used for further examinations.

DNA isolation for sequencing and denaturing gradient gel electrophoresis (DGGE) of PCR product of $\boldsymbol{c p c B} \boldsymbol{A}$-IGS. DNA from isolated strains was extracted from $2 \mathrm{ml}$ of culture using commercial DNA extraction kit (EURx) for isolation genomic DNA from bacteria. In order to check if the isolates represented pure cultures the DGGE analyses of the $c p c B A$-IGS were performed because cyanobacterial cells usually contain only one operon of these genes. Isolates characterized by only one band were assigned as pure cyanobacterial cultures. Amplification of $c p c B A$-IGS for DGGE and direct sequencing was performed using the following primers: cpcAR(URP) and cpcBF(DGGE) modified by addition of the GC clamp to the original sequence of primers (Robertson et al., 2001; Crosbie et al., 2003b). Polyacrylamide gels (8\%) were prepared in a 0.5 -concentrated Tris Acetic acid EDTA (TAE) buffer for DGGE analysis. The gradient of denaturant concentration, determined empirically, increased from $37.5 \%$ to $65 \%$. Electrophoresis was carried out in a $0.5 \mathrm{X}$ TAE buffer for $4 \mathrm{~h}$ at $200 \mathrm{~V}$ with a DCode electrophoresis system (Bio-Rad, USA). After the electrophoresis, the gels were stained with SYBR Green (Sigma) for 15 minutes, rinsed with distilled water and photographed in UV light. Amplification for direct sequencing of 16S rRNA encoding gene was performed using a specific pair of primers: 16S5 F (Scheldman et al., 1999) and B23S5_R (Lepere, 2000).

Alignment and phylogenetic analyses. The sequences obtained in the study have been submitted to the DDBJ/EMBL/GenBank databases under following accession numbers: FJ63765 - FJ763789, GQ130142 - GQ130156, FJ763795 - FJ763832. The alignments of sequences, obtained by using ClustalX 1.83 (Thompson et al., 1997) with default options, were manually checked. After the removal of sites with uncertain homology which could not be unambiguously aligned, the $16 \mathrm{~S}$ rDNA data set of 1341 characters was generated for phylogenetic analyses in the alignment of 35 sequences and the $c p c B A$-IGS data set of 388 characters in the alignment of 41 sequences.

Distance (NJ) analyses were performed by PAUP*, Version 4.0b6 for Microsoft Windows (Swofford, 1998). Bootstrap support for specific nodes (Felsenstein, 1985) was estimated by the default options using 1,000 replications as implemented in PAUP*. Models of sequence evolution and their parameter values for NJ method were estimated by Modeltest 3.7 (Posada and Crandall, 1998). For 16S rDNA alignment the likelihood ratio test (hLRTs), of the Modeltest software program, suggested $\mathrm{TrN}+\mathrm{I}+\mathrm{G}$ model (Tamura and Nei, 1993) and Akaike test suggested a general time reversible $(\mathrm{GTR}+\mathrm{I}+\mathrm{G})$ model (Lanave et al., 1984; Tavare, 1986; Rodriguez et al., 1990). For $c p c B A$-IGS alignment hLRT and Akaike tests suggested a $\mathrm{TrN}+\mathrm{G}$ model. These models were applied to calculate NJ trees, with parameter values drawn from Modeltest. The sequences from strain PCC 6301 were used to root the trees (Ernst et al., 2003; Haverkamp et al., 2008), which were drawn by Tree View, Version 1.6.1 for Microsoft Windows (Page, 1996).

Statistical analyses. In addition to phylogenetic analyses described above, the $t$-test and Spearman correlation analyses were performed. For the analyses STATISTICA package version 8 (StatSoft Inc., Tulsa, OK, USA) was used and the results were found statistically significant with $\mathrm{p}<0.05$ if not stated otherwise in the text.

\section{Results}

Number and composition of picocyanobacteria. The CY3 (HYQ) filter tested in the present study proved to be superior to blue and green filters com- 

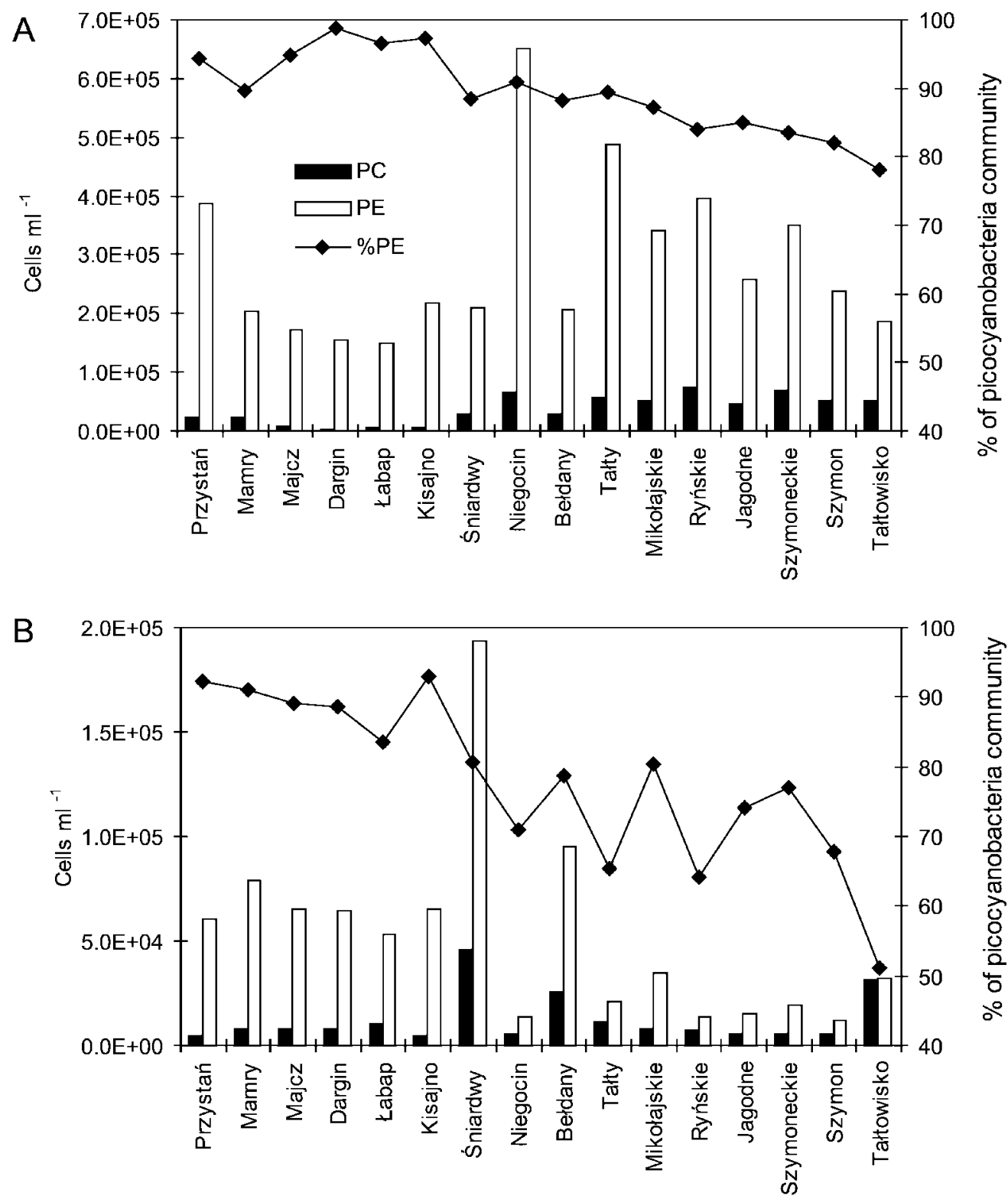

Fig. 1. The abundance of phycoerythrin-rich (PE) and phycocyanin-rich (PC) ecotypes of picocyanobacteria and the percentage of $\mathrm{PE}$ in the picocyanobacterial community in lakes from the Great Mazurian Lakes system in a survey in 2006 (A) July, (B) September

monly used for picocyanobacteria examinations. It allowed for better differentiation between phycoerythrin-rich (PE) and phycocyanin-rich (PC) picocyanobacteria as the PE cells appeared bright orange and PC bright red, with no need to change filters. However, similarly to standard green filter, the CY3 (HYQ) was not satisfactory for visualising picoeukaryotes, which appeared dull red. As it was the first attempt to use the new filter, the samples were additionally checked with the blue and green filter set.

In a survey made in 2006, in which the 15 lakes belonging to the Great Mazurian Lakes system and Lake Majcz were sampled, the abundance of picocyanobacteria in July ranged between 1.6 to $7.2 \times 10^{5} \mathrm{ml}^{-1}$. In September the numbers were lower, varying between $1.5 \times 10^{4} \mathrm{ml}^{-1}$ and $2.4 \times 10^{5} \mathrm{ml}^{-1}$. The mean abundance was $3.3 \times 10^{5}$ cell $\mathrm{ml}^{-1}$ in July and $6.4 \times 10^{4}$ cells ml ${ }^{-1}$ in September, placing the results well within the range found in temperate lakes. The PE ecotype accounted on average for $89 \%$ of the whole picocyanobacterial community in early July and for $78 \%$ in September. The share of PE picocyanobacteria ranged between $97 \%$ and $78 \%$ in July and $93 \%$ to $51 \%$ in September (Fig 1A, B). It was established that the share of PE cells was decreasing with increasing trophic status of studied lakes (in July $\mathrm{R}=-0.84 ; \mathrm{p}=0.00005$ and in September $\mathrm{R}=-0.84$; $\mathrm{p}=0.00004$ ) and was lower in September than in July $(p=0.002)$. However, even in hypertrophic lakes, the $\mathrm{PE}$ dominated the picocyanobacteria community in September. The additional analysis of PE percentage and $\mathrm{K}_{\mathrm{SD}}$ showed that the negative correlation between 
the two variables was even stronger $(\mathrm{R}=-0.88$; $p=0.00007)$. In 2007, the year of the isolation of picocyanobacteria, the $\mathrm{PE}$ ecotype accounted on average for $80 \%$ of all picocyanobacteria during the whole study period (between April and October), ranging between $97 \%$ and $57 \%$. Similarly as in 2006, the PE dominated overwhelmingly in less productive lakes (Majcz Wielki and Śniardwy) accounting for $89 \%$ of all picocyanobacteria during the whole study period while their share in lakes of higher trophic status (Mikołajskie and Bełdany) was lower (73\%). Furthermore, in all four sampled lakes throughout late summer and autumn PE accounted for a lower percentage, $72 \%$ of picocyanobacteria community compared with $87 \%$ in the spring and early summer.

Isolates and efficiency of isolation methods. Altogether 50 isolates (19 PE and $31 \mathrm{PC}$ ) were obtained by means of the two methods. Besides microscopic analyses the DGGE analysis of the $c p c B A$-IGS operon also proved that most of the obtained cyanobacterial isolates were pure, but not axenic. In the classic plate method from 600 streaked plates performed in 2007, APP growth was observed on 158 Petri dishes. In 24 cases, the APP colonies were successfully transferred to a liquid medium. As a result 3 isolates of PE picocyanobacteria and 16 isolates of PC picocyanobacteria were obtained. In the case of cytometric method used in 2007 the APP growth was observed in 30 wells among 890 microwells to which putative APP cells were sorted. From that we obtained 25 cyanobacterial cultures: $13 \mathrm{PE}$ and 12 PC. In 2008 we isolated another $3 \mathrm{PE}$ and $3 \mathrm{PC}$ picocyanobacteria strains using flow-cytometry, but the efficiency was not calculated. The efficiency of isolation was thus $3.2 \%$ in the plate method and $2.8 \%$ in the flowcytometry method. There were differences in isolation of cells with different pigment types due to the varying isolation efficiency of the two methods. In the plate method the PE picocyanobacteria were isolated with $0.5 \%$ efficiency while in the cytometric method with $1.5 \%$ efficiency. The PC cells were isolated with $2.7 \%$ and $1.4 \%$ efficiency in the plate and cytometric method respectively. Comparing the two methods it was found that in the classic plate method the PE and PC cells were isolated in the ratio 1:5.3, while the ratio in the flow-cytometry method was 1.1:1.

Enrichment cultures have not proved effective in our isolation procedure, especially in the flow-cytometry method. The picocyanobacteria abundance decreased in the enrichment cultures between 2.5 and 12 times and the subsequent efficiency of isolation by the cytometric method was only up to $0.3 \%$. When direct sorting of filtered lake water after centrifugation was performed the isolation efficiency was $9.6 \%$.

All of the picocyanobacteria were isolated only on WC medium although three media were used in isolation: WC, BG11 and modified BG11. Furthermore, during the re-isolation of picocyanobacteria from previously obtained cultures all isolates resumed growth again only on the WC medium. Later during cultivation, all PC and PE isolates could grow on the WC and standard BG11 medium. However, strains cultivated on BG11 were in better condition and could be transferred to new media less frequently.

Phylogenetic relationships between the isolated strains. The $c p c B A$-IGS operon was further examined for 39 isolates, while 33 isolates were used for the analysis of $16 \mathrm{~S}$ rRNA encoding gene. The sequencing of the $c p c B A$-IGS operon revealed that the isolates were characterized by varying length of the IGS region. The length varied between 38 and as many as 97 nucleotide base pairs. On the tree based on c $p c B A$-IGS analysis, the isolates were divided into five groups, each with a similar IGS length within the group (Fig. 2). The formed clusters had a high bootstrap support ranging between 77 and 100. The groups were formed by isolates of similar pigment composition. The PE isolates got divided into two clusters with strains characterized by 38 and $42 \mathrm{bp}$ in the IGS region. In the cluster with $42 \mathrm{bp}$ in the IGS region, isolates all four lakes could be found, while to the second PE cluster (38 bp) only isolates from both eutrophic lakes (Mikołajskie and Bełdany) were assigned. The PC isolates were assigned to three clusters: the first with 39 bp in IGS with two isolates from Lake Bełdany, the second with 44 and 45 bp (with isolates originating from lakes Majcz, Mikołajskie and Bełdany). The third cluster was characterized by $97 \mathrm{bp}$ in the IGS region. In this cluster mostly isolates from the mesotrophic lake Majcz Wielki were found, with the exception of strain MI 0608F from Lake Mikołajskie. Two isolates, SN0807 and MA0607K, could not be assigned to any of the groups. The SN0807, characterized by $40 \mathrm{bp}$, was located at the bottom of a cluster of isolates with 44 and $45 \mathrm{bp}$ in the IGS region. The MA0607K strain contained the IGS fragment with 54 base pairs, not found in any other isolate.

The analysis of 16S rDNA allowed to divide the isolated strains into four well-supported clusters: two with PC cells, one representing the PE ecotype and one with PE and PC isolates (Fig. 3). The first PC cluster grouped isolates originating from all four lakes, while the second cluster only isolates from the eutrophic Lake Bełdany. The cluster with PE cells only grouped isolates from Lakes Majcz, Śniardwy and Mikołajskie. To the last cluster isolates of both $\mathrm{PE}$ and $\mathrm{PC}$ ecotypes were assigned. These isolates came from Lakes Majcz and Mikołajskie. The bootstrap values for the described clusters ranged between 70 and 99 and the genetic variability within these groups was bigger than in the case of $c p c B A$-IGS analysis. The fifth cluster grouping one of the PE 

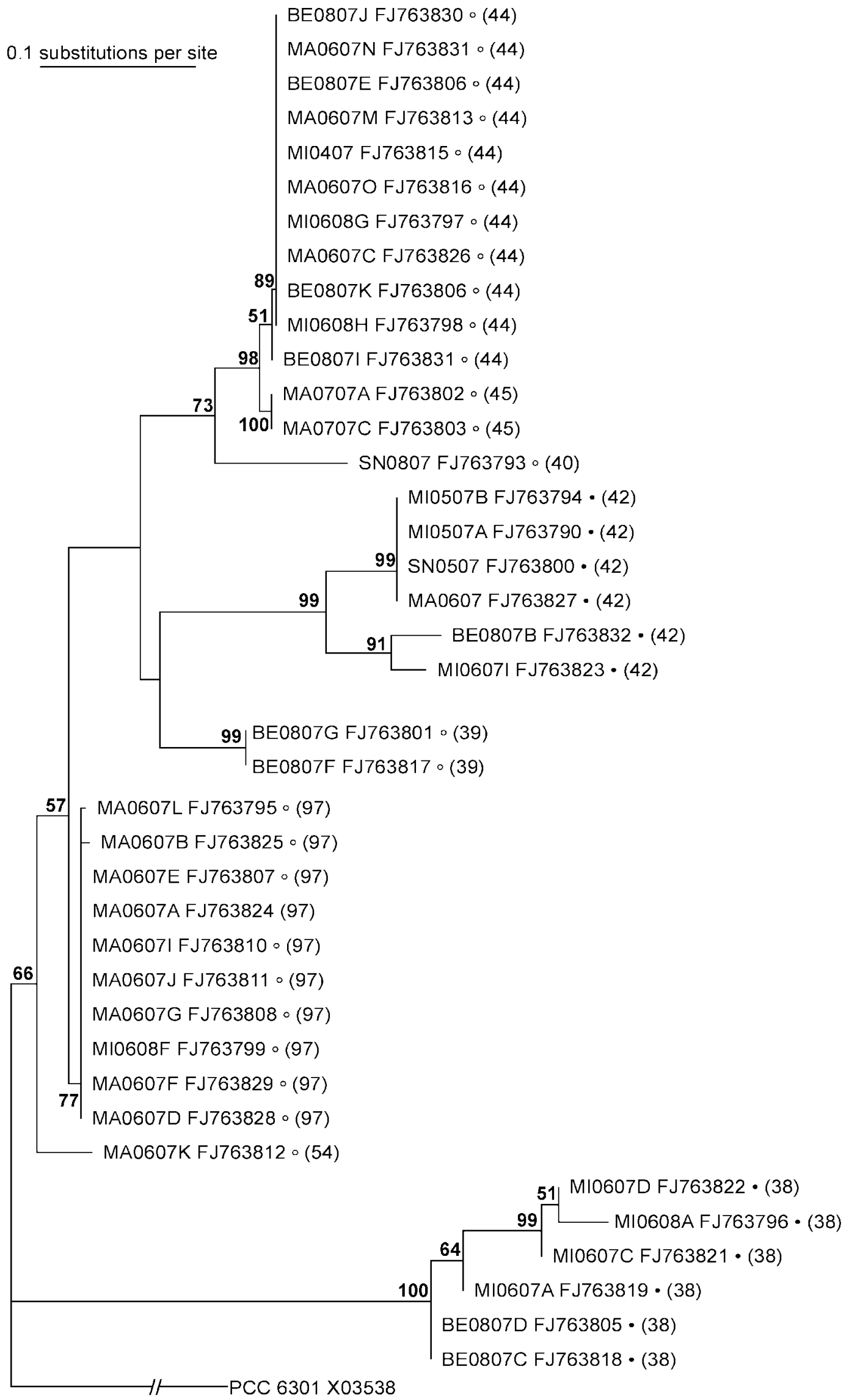

Fig. 2. The phylogenetic tree of $c p c B A$-IGS sequences obtained by NJ analysis. Terminal branches display isolate and GenBank accession numbers, pigment group ( PE-rich; O PC-rich) and the length of the IGS region. Numbers at the nodes show the bootstrap values $(>50 \%)$ 


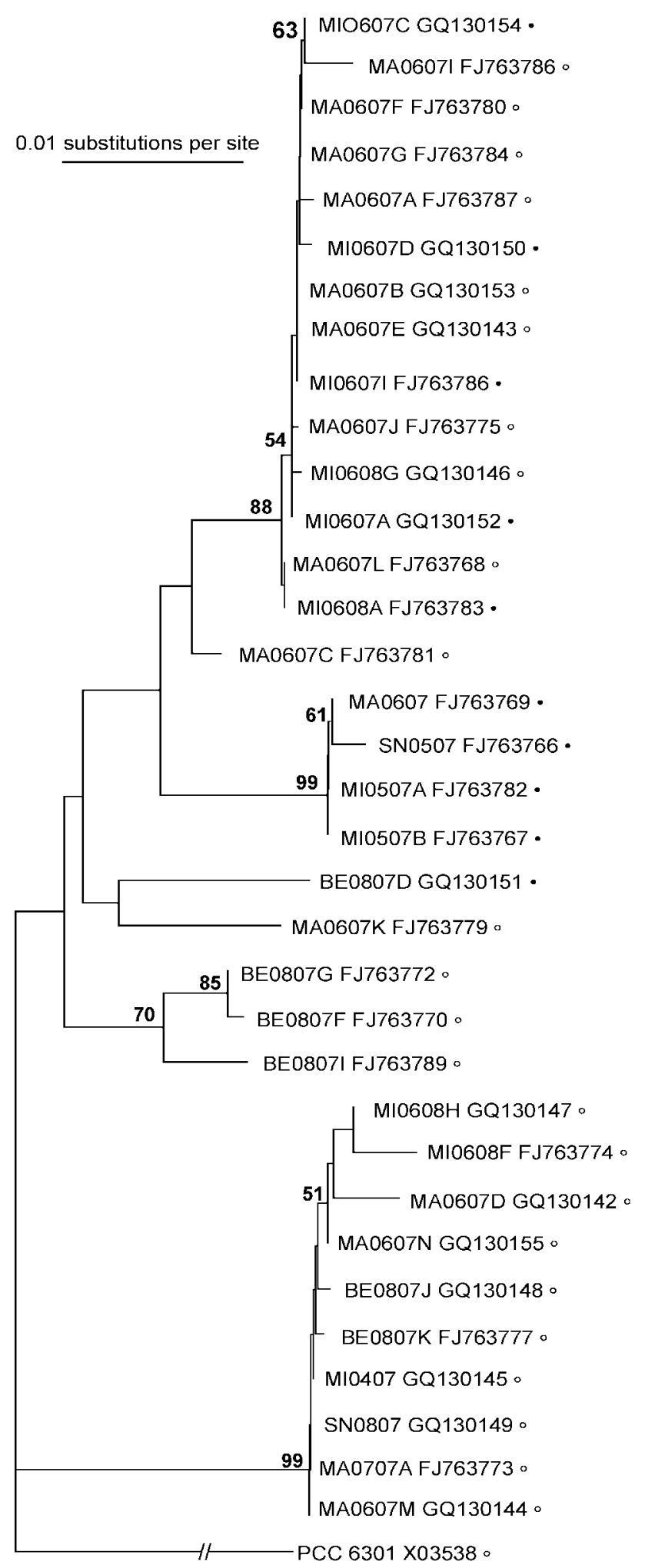

Fig. 3. The phylogenetic tree of $16 \mathrm{~S}$ rDNA sequences obtained by $\mathrm{NJ}$ analysis. Terminal branches display isolate and GenBank accession numbers and pigment group ( $\bullet$ PE-rich; O PC-rich).

Numbers at the nodes show the bootstrap values $(>50 \%)$

(BE0807D) and one of the PC (MA0607K) strains had no support. In $c p c B A$-IGS analysis strain BE0807D from this cluster was grouped with several other PE strains from Lake Mikołajskie, while the
MA0607K had no resolved position. One strain (MA0607C) was not assigned to any cluster and was located at the bottom of the cluster containing $\mathrm{PE}$ and $\mathrm{PC}$ isolates.

\section{Discussion}

This study confirmed earlier findings that the picocyanobacteria community in The Great Mazurian Lake system (GML) was dominated by the phycoerythrin-rich (PE) ecotype (Jasser, 2002) despite the generally high trophic status of these lakes. The PE picocyanobacteria prevailed overwhelmingly over the phycocyanin-rich (PC) in less productive lakes, but also dominated in the eutrophic and hypertrophic ones. The analysis of 15 interconnected lakes and one not directly connected with the system, all representing different trophic status (Chróst and Siuda, 2006), with TSI ranging between 40 and 70 , showed a gradual and statistically significant decrease of PE contribution to the picocyanobacteria community parallel to the increasing trophic status. A decrease of PE APP and increase of PC APP percentage in waters along with the increasing trophic status was reported before (Vörös et al., 1998). However the Great Mazurian Lakes system is a very clear example of this process due to the easily observable, gradual change of the picocyanobacterial community within a connected lake system spreading for over $100 \mathrm{~km}$. According to Vörös et al. (1998) the PE ecotype does not usually exceed $10 \%$ of all picocyanobacteria in waters characterized by a $50 \mathrm{mg}^{-1}$ of chlorophyll $a$ concentration. In even the most productive lakes of the GML the PE contribution did not fall below 50\%, despite chlorophyll $a$ values often exceeding $80 \mathrm{mg} \mathrm{l}^{-1}$. However, the above, as well as other authors (Vörös et al., 1998; Mózes et al., 2006; Stomp et al., 2007), attributed the differences in abundance of both ecotypes and the PE:PC ratio not only to chlorophyll $a$ content, but also to turbidity and the color of water which influence the underwater light climate. The $\mathrm{K}_{\mathrm{SD}}$, which ranged in the studied lakes between 0.35 and 2.9 (Table I), suggests a considerably good penetration of light and favorable light conditions for the PE ecotype in these lakes despite high chlorophyll $a$ concentrations. Thus it may explain the ostensible overrepresentation of PE picocyanobacteria in this system. However further analysis of the relationship between chlorophyll $a$, the underwater light climate and some physical and chemical parameters influencing the PE:PC ratio in the GML is needed.

Additionally the comparison of data from early July and early September in 2006 revealed differences in the ratio between PE and PC within the summer season. In contrast to earlier works (Mózes et al., 
2006), we have found that the PC contribution to picocyanobacteria community was generally higher in late than early summer across the trophic gradient. Mózes et al. (2006) reported that in the mesotrophic, western basin of Balaton, the PC APP achieved their peak of abundance in May and June, with PE peaking in July-August 2003, while in the eutrophic, eastern basin, PC APP achieved their maximum number in August, with PE exhibiting only a minor peak in the same month. Consequently, the ratio between the two ecotypes varied and in the mesotrophic basin PC played a more important role in the picocyanobacterial community in the spring and early summer than in the late summer, while in the eutrophic part they prevailed in the community from April to November 2003. In the GML, the higher contribution of PC cells resulted from a more drastic decrease of PE than PC cells in late summer. These findings were confirmed by the following year results, which involved fewer lakes which were sampled more frequently, demonstrating a bigger role of the PE ecotype in spring and early summer and an increase of PC importance in the community in late summer.

The study resulted in the isolation of picocyanobacteria from four studied lakes in the Great Mazurian Lakes system. According to our knowledge, this is the first successful isolation of picocyanobacteria from this geographical region. By means of the classic plate method and the flow-cytometry method we managed to obtain several dozen PE and PC picocyanobacteria isolates. The study allowed to compare both methods and showed that despite modifications of the method proposed by Crosbie et al. (2003b), needed for adjustments of our equipment, the flow-cytometry method remains superior to the classic plate method. It was verified that the flow-cytometry method is faster and less laborious than the plate method. Most importantly, it gives better results in isolation of PE cells. PE picocyanobacteria are very difficult to isolate, and usually do not form colonies on agar (Ernst, 1991). Because of this, PE are usually much more rare in culture collections. PC picocyanobacteria are much easier to obtain by the use of the plate method. In our study the rate between obtained PE and PC isolates in the classic plate method was 1:5 while in the flowcytometry method it was $1.1: 1$, proving that flow-sorting is superior in the isolation of PE cells. The overall efficiency of both methods was on a similar level but the first positive results in the flow-cytometry method were visible already after 4 to 10 weeks following sorting compared to 10 to 40 weeks in Petri dishes. The modifications such as centrifugation of cells to the abundance required by our sorter did not hinder the isolation but actually showed that the enrichment cultures phase could be skipped, additionally shortening the time of isolation. In fact in our study the enrichment cultures were not successful and the isolation by flow-sorting gave much better results without them. Thus, besides recommending the flow-cytometry method for isolation of picocyanobacteria, we suggest omitting the enrichment cultures in favor of the centrifugation of cells to a desired density.

Among the three tested media, BG11, a modified BG11 (Ernst et al., 2005) and the WC medium, the last one turned out to be most useful for picocyanobacteria isolation. We have managed to isolate picocyanobacteria only on the WC medium, however, the isolates obtained this way grew better on BG11 during the cultivation. The WC medium is the poorest in terms of $\mathrm{N}$ and $\mathrm{P}$ from the three chosen media and also has a lower N:P ratio than both BG11s. Ernst et al. (2005) stated that a too-high concentration of nitrates can be inhibiting for picocyanobacteria, thus they proposed to reduce the $\mathrm{N}$ and $\mathrm{P}$ to a $1 / 3$ concentration of the original BG11. However, it seems that the lower concentration of phosphorus as well as a lower ratio between the basic nutrients is also very important at the initial state of isolation. By providing the nutrients in proportion close to Redfield ratio, WC is more selective for picocyanobacteria. This result was confirmed during the re-isolation of previously obtained strains by flowcytometry when the isolates resumed their growth only on the WC medium, even if some of them were reisolated from BG11cultures. Thus our results validate earlier findings that, while $\mathrm{WC}$ is a gentler medium, BG11 is superior for supporting the growth of picocyanobacterial cultures for a longer period (Jezberová and Komárková, 2007). It seems that both media should be used interchangeably in the process: WC for isolation and BG11 for cultivation of picocyanobacteria. Additionally, the use of eukaryotic inhibitors during isolation by the plate method (Sherr et al., 1986) proved to be successful as it reduced the growth of eukaryotes but did not influence the prokaryotes.

The DGGE analysis of PCR product of $c p c B A$-IGS, part of the phycocyanin operon allowed to check if the isolates were pure as cyanobacterial cultures. Consequently, the sequencing of the phycocyanin operon revealed that the isolates differed substantially in IGS length. The phylogenetic tree of isolated strains based on the $c p c B A$ operon showed that the strains formed five clusters with a high bootstrap support and the clusters were characterized by a similar IGS length within a given group. These results are in line with previous findings of Robertson et al. (2001) and Crosbie et al. (2003a) who reported that the IGS length was stable within well-supported clusters. Thus it seems that the IGS length might be the first good indicator of close phylogenetic relationships between isolates and in this way a routine electrophoresis of PCR products of $c p c B A$-IGS region can be used for initial distinguishing between picocyanobacteria. 
The IGS length of our isolates ranged between 38 and $97 \mathrm{bp}$. Interestingly, one of the clusters, with 77 bootstrap support, was formed by isolates with $97 \mathrm{bp}$ in IGS, a length not commonly found in the literature. In fact only one strain from Lake Tsukui in Japan had similar IGS length but its position in the $c p c B A$-IGS tree proposed by Crosbie et al. (2003a) was not resolved. This was a PE strain, however, not PC as in our study, which requires further examination. Our results suggest that isolates characterized by $97 \mathrm{bp}$ in the IGS region might represent a new cluster. The rest of our isolates exhibited IGS length found in phylogenetic groups B $-42, \mathrm{C}-40$ and $\mathrm{E}-38$ (Crosbie et al., 2003a). Another of our well-supported PC clusters contained isolates with 44 and $45 \mathrm{bp}$ in their IGS. According to Crosbie et al. (2003a) a $45 \mathrm{bp}$ IGS was within the group A - Cyanobium gracile cluster. The last cluster of cpcBA-IGS-based tree gathered strains from eutrophic Lake Bełdany with $39 \mathrm{bp}$ in IGS. Up to this moment we have not found, however, records of such a cluster or sequences with a similar IGS length in the published literature.

The phylogenetic tree derived from the16S rDNA analysis exhibited roughly similar topology as the $c p c B A$-IGS-derived tree discussed above. We have found that our isolates grouped in four well-supported clusters contained mostly similar sets of sequences to clusters defined in the phylogenetic analysis of the phycocyanin operon. However, one of the clusters in the 16S rDNA analysis gathered strains of both PE and PC ecotype. The PC strains from this group in the $c p c B A$-IGS-based tree contained $97 \mathrm{bp}$ in the IGS region and a formed cluster not present in the phycocyanin operon based tree proposed by Crosbie et al. (2003a). The PE strains assigned to the PE-PC cluster in $16 \mathrm{~S}$ rDNA analysis in our $c p c B A$-IGSderived tree formed a separate group, characterized by $38 \mathrm{bp}$ in the IGS region. It is difficult to say at the moment if this cluster is new and what its phylogenetic position is when compared with already proposed phylogenetic trees. The relationships between other strains isolated by us and sequences already known from other geographical regions also require further investigations. The present study suggests the occurrence in the Mazurian Lakes of at least one group of strains genetically different from those described so far.

\section{Acknowledgments}

The study was supported by the Ministry of Sciences and Higher Education (project: N304 015 31/0535).

We would like to thank the Microbial Ecology Department team for help in sampling and professor Ryszard J. Chróst, as well as the anonymous reviewers for their comments.

\section{Literature}

Agawin N.S.R., C.M. Duarte and S. Agusti. 2000. Nutrient and temperature control of the contribution of picoplankton to phytoplankton biomass and production. Limnol. Oceanogr. 45: 591-600.

Bell T. and J. Kalff. 2001. The contribution of picophytoplankton in marine and freshwater system of different trophic status and depth. Limnol. Oceanogr. 46: 1243-1248.

Callieri C. and J.G. Stockner. 2002. Freshwater autotrophic picoplankton: a review. J. Limnol. 6: 1-14.

Carrick H.J. and C.L. Schelske. 1997. Have we overlooked the importance of small phytoplankton in productive waters? Limnol. Oceanogr. 42: 1613-1621.

Carlson R.E. 1977. A trophic state index for lakes. Limnol. Oceanogr. 22: 361-369.

Chróst R.J. and W. Siuda. 2006. Microbial production, utilization, and enzymatic degradation of organic matter in the upper trophogenic water layer in the pelagial zone of lakes along the eutrophication gradient. Limnol. Oceanogr. 51:749-762.

Crosbie N.D, M. Pöckl and T. Weisse. 2003a. Dispersal and phylogenetic diversity of nonmarine picocyanobacteria, inferred from 16SrRNA gene and cpcBA intergenic spacer sequence analyses. Appl. Environ. Microb. 69: 5716-5721.

Crosbie N.D., M. Pöckl and T. Weisse. 2003b. Rapid establishment of clonal isolates of freshwater autotrophic picoplankton by single-cell and single-colony sorting J. Microbiol. Methods 55: $361-370$.

Ernst A. 1991. Cyanobacterial picoplankton from Lake Constance. I. Isolation by fluorescence characteristics. J. Plankton Res. 13: 1307-1312.

Ernst A., S. Becker, U.I.A. Wollenzien and C. Postius. 2003. Ecosystem dependent adaptive radiations of picocyanobacteria inferred from 16S rRNA and ITS-1 sequence analysis. Microbiology 149: 217-228.

Ernst A., M. Deicher, P.M. Herman and U.I.A. Wollenzien. 2005. Nitrate and Phosphate Affect Cultivability of Cyanobacteria from Environments with Low Nutrient Levels. Appl. Environ. Microbiol. 71: 3379-3383.

Felsenstein J. 1985. Confidence limits on phylogenies: an approach using the bootstrap. Evolution 39: 783-791.

Guillard R.R. and C.J. Lorenzen. 1972. Yellow-green algae with chlorophyllide. J. Phycol. 8: 10-14.

Hepperle D. and L. Krienitz. 2001. Systematics and ecology of chlorophyte picoplankton in German inland waters along a nutrient gradient. Internat. Rev. Hydrobiol. 86: 269-284.

Haverkamp T., S.G. Acinas and M. Doeleman. 2008. Diversity and phylogeny of Baltic Sea picocyanobacteria inferred from their ITS and phycobiliprotein operons. Environ. Microbiol. 10: 174-188.

Jasser I. 2002. Autotrophic picoplankton (APP) in four lakes of different trophic status: composition, dynamics and relation to phytoplankton. Pol. J. Ecol. 50: 341-355.

Jasser I. and L. Arvola. 2003. Potential effects of abiotic factors on the abundance of autotrophic picoplankton in four boreal lakes. J. Plankton Res. 25: 873-883.

Jasser I. 2006. The relationship between APP-the smallest autotrophic component of food web and trophic status and the depth of lakes. Ecohydrol. Hydrobiol. 6: 69-77.

Jasser I., I. Kostrzewska-Szlakowska, J. Ejsmont-Karabin, K. Kalinowska and T. Węgleńska. 2009. Autotrophic versus heterotrophic production and components of trophic chain in humic lakes: the role of microbial communities. Pol. J. Ecol. 57: 423-439. 
Jezberová J. and J. Komárková. 2007. Morphometry and growth of three Synechococcus-like picoplanktonic cyanobacteria at different culture conditions. Hydrobiologia 578: 17-27.

Johnson P.W. and J. McN. Sieburth. 1979. Chroococcoid cyanobacteria in the sea; a ubiquitous and diverse phototrophic biomass. Limnol. Oceanogr 24: 928-935.

Lanave C., G. Preparata., C. Saccone and G. Serio. 1984. A new method for calculating evolutionary substitution rates. J. Mol. Evol. 20: 86-93.

Lepere C., A. Wilmotte and B. Meyer. 2000. Molecular diversity of Microcystis strains (Cyanophyceae, Chroococcales) based on 16S rDNA sequences. Syst. Geogr. Plants 70: 275-283.

Malinsky-Rushansky N. and T. Berman. 1991. Picocyanobacteria and bacteria in lake Kinneret. Int. Rev. ges. Hydrobiol. 76 : 555-564.

Mózes A., M. Présing and L. Vörös. 2006. Seasonal dynamics of picocyanobacteria and picoeukaryotes in a large shallow lake (Lake Balaton, Hungary). Internat. Rev. Hydrobiol. 91: 38-50.

Page R.D.M. 1996. TREEVIEW: an application to display phylogenetic trees on personal computers. Comp. Appl. Biosci. 12: 357-358.

Posada D. and K.A. Crandall. 1998. Modeltest: testing the model of DNA substitution. Bioinformatics 14: 817-818.

Rodriguez F., J.L. Oliver, A. Marin and J.R. Medina. 1990. The general stochastic model of nucleotide substitution. J. Theor. Biol. 142: 485-501.

Robertson B.R., N. Tezuka and M.M. Watanabe. 2001. Phylogenetic analyses of Synechococcus strains (cyanobacteria) using sequences of the 16S rDNA and part of the phycocyanin operon reveal multiple evolutionary lines and reflect phycobilin content. Int. J. Syst. Evol. Microbiol. 51: 861-871.

Scheldman P., D. Baurain, R. Bouhy, M. Scott, M. Muhling, B.A. Whitton, A. Belay and A. Wilmotte. 1999. Arthrospira ('Spirulina') strains from four continents are resolved into only two clusters, based on amplified ribosomal DNA restriction analysis of the internally transcribed spacer. FEMS Microbiol. Lett. 172: 213-222.

Sherr B.F., E.B. Sherr, T.L. Andrew, R.D. Fallon and S.Y. Newell. 1986. Trophic interactions between heterotrophic protozoa and bacterioplankton in estuarine water analyzed with selective metabolic inhibitors. Marine Ecology-Progress Series. 32: $169-179$.
Søndergaard M. 1991. Phototrophic picoplankton in temperate lakes: seasonal abundance and importance along trophic gradient. Int. Rev. ges. Hydrobiol. 76, 502-522.

Stomp M., J. Huisman, L. Vörös, F.R. Pick, M. Laamanen, T. Haverkamp and L.J. Stal. 2007. Colourful coexistence of red and green picocyanbacteria in lakes and seas. Ecol. Lett. 10 290-298.

Stanier R.Y., R. Kunisawa, M. Mandel and G. Cohen-Bazier. 1971 Purification and properties of unicellular blue-green algae (order Chroococcales). Bacteriol. Rev. 35: 171-205.

Stockner J.G. 1991 Autotrophic picoplankton in freshwater ecosystems: the view from the summit. Int. Rev. ges. Hydrobiol. 76: 483-493.

Swofford D.L. 1998. PAUP*. Phylogenetic Analysis Using Parsimony (* and Other Methods), Version 4. Sunderland, Massachusetts, USA:Sinauer.

Tamura K. and K. Nei. 1993. Estimation of the number of nucleotide substitutions in the control region of mitochondrial DNA in humans and chimpanzees. Mol. Biol. Evol. 10: 512-526.

Tavare S. 1986. Some probabilistic and statistical problems on the analysis of DNA sequences. Lec. Math. Life Sci. 17: 57-86.

Thompson J.D., T.J. Gibson, F. Plewniak, F. Jeanmougin and D.G Higgins. 1997. The ClustalX windows interface: flexible strategies for multiple sequence alignment aided by quality analysis tools. Nucleic Acids Res. 24: 4876-4882.

Vörös L., C. Callieri, K.V. Balogh and R. Bertoni. 1998. Freshwater picocyanobacteria along a trophic gradient and light quality range. Hydrobiologia 369/370: 117-125.

Watanabe M.M., M. Nakagawa, M. Katagiri, K. Aizawa, M. Hiroki and H. Nozaki. 1998. Purification of freshwater picoplanktonic cyanobacteria by pour-plating in "ultra-low-gellingtemperature agarose". Phycol. Res. 42: 71-75.

Wakabayashi T. and S. Ichise. 2004. Seasonal variation of phototrophic picoplankton in Lake Biwa. Hydrobiologia 528: $1-16$.

Waterbury J.B., S.W. Watson, R.R.L. Guillard and L.E. Brand. 1979. Widespread occurrence of unicellular, marine, planktonic cyanobacterium. Nature 277: 293-294.

Weisse T. 1993. Dynamics of autotrophic picoplankton in marine and freshwater ecosystems. In Jones, W.J.G. [Ed.] Advances in microbial ecology. Plenum Press, New York. 13: 327-370. 